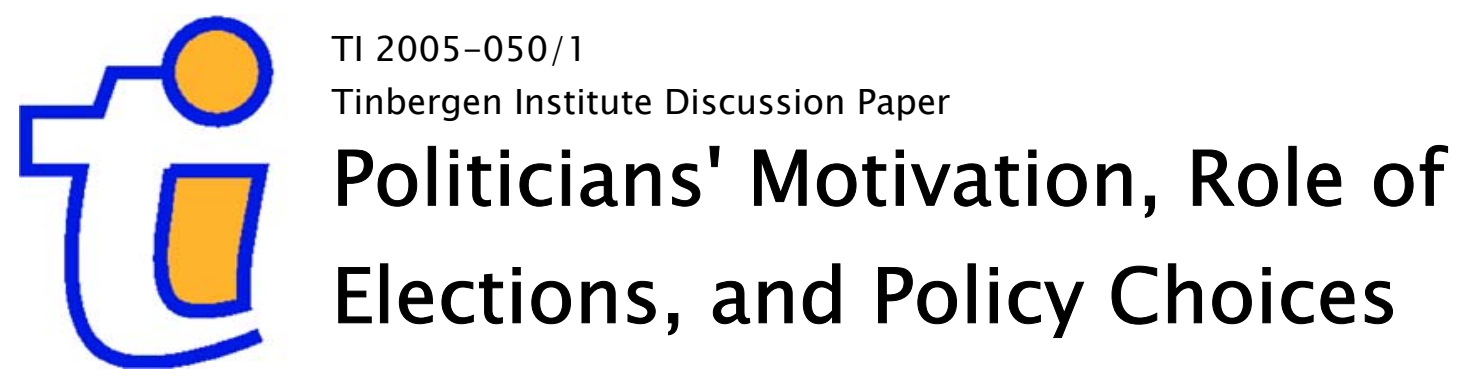

Phongthorn Wrasai

Department of Economics, Erasmus University Rotterdam, and Tinbergen Institute. 


\section{Tinbergen Institute}

The Tinbergen Institute is the institute for economic research of the Erasmus Universiteit Rotterdam, Universiteit van Amsterdam, and Vrije Universiteit Amsterdam.

Tinbergen Institute Amsterdam

Roetersstraat 31

1018 WB Amsterdam

The Netherlands

Tel.: $\quad+31(0) 205513500$

Fax: $\quad+31(0) 205513555$

Tinbergen Institute Rotterdam

Burg. Oudlaan 50

3062 PA Rotterdam

The Netherlands

Tel.: $\quad+31(0) 104088900$

Fax: $\quad+31(0) 104089031$

Please send questions and/or remarks of nonscientific nature to driessen@tinbergen.nl.

Most TI discussion papers can be downloaded at http://www.tinbergen.nl. 


\title{
Politicians' Motivation, Role of Elections, and Policy Choices
}

\author{
Phongthorn Wrasai* \\ Erasmus University Rotterdam and Tinbergen Institute
}

23 May 2005

\begin{abstract}
We develop a simple two period model to study the importance of motivational differences among politicians in describing the role of elections and explaining policy choices. In our model, politicians differ in their motives of running public office. Good politicians care about policies while bad politicians care about rent extraction. Voters want to control politician misbehavior and to select good politicians. We show that reelection concerns may compel a good politician not to implement a socially desirable policy if he sufficiently cares about the future. Second, reelection concerns may induce a bad politician not to undertake a socially undesirable policy. The reason for this is fear of being ruled by another bad politician if unseated. This finding exhibits the disciplining function of elections. A striking result in our paper is that bad politicians may act more in tune with the public interest relative to the good politicians. (JEL: D72, D78, D82)
\end{abstract}

\section{Introduction}

Disciplining and selecting politicians is a main concern in representative democracies. This concern stems from two core problems. First, motives

\footnotetext{
${ }^{*}$ I would like to thank Klaas Beniers, Otto H. Swank, and seminar participants at Erasmus University Rotterdam and at European Public Choice Soceity Conference 2005 for useful discussions and their comments. Corresponding address: Phongthorn Wrasai, Department of Economics, Erasmus University Rotterdam P.O. Box 1738, 3000 DR, Rotterdam, The Netherlands. E-mail: pwrasai@few.eur.nl.
} 
of holding office differ among politicians. Some politicians are motivated by a public spirit while others are more opportunistically motivated. It is well known that citizens have weak incentives to acquire information. Second, government decision making process endows politicians with bureaucrats acting as their information providers. Accordingly politicians may exploit informational superiority to further their own interest, which may not coincide with the public interest.

To alleviate agency problems, elections are used as an incentive mechanism, aimed at holding politicians accountable for their behavior and selecting good ones to run political office. Concerning the literature on electoral accountability $^{1}$, how elections function and how reelection incentives shape politicians' behavior and policy choices critically hinge on the nature of informational asymmetries between politicians and voters, and on the characteristics of the politicians assumed in these studies. While most of the literature has paid attention to differences in competence between politicians when studying electoral control and policy processes, little has been focused on the motivational differences of politicians in explaining those issues.

The aim of this paper is to examine the role of elections and the implications of reelection concerns on policy choices when the politicians' motivation matters. In our analysis, politicians differ in their motives of holding office. Good politicians care about implemented policies whereas bad ones care not only about the policies but also want to extract rents. When policies are stochastic in nature, there are two implications. First, they create an incentive for politicians to use policy implementation as ' a rent extraction device' to appropriate resources at the expense of voters. Second, by observing the implementation of policies, the voters are unable to tell whether the incumbent is acting in their interest or simply extracting rent through policy implementation. To illustrate these repercussions, we employ a simple two-period model. There are two players: an incumbent politician and a representative voter. The motivation of the incumbent politician is private information. In the first period the incumbent politician must make a decision as to whether or not to implement a particular policy. The representative voter observes the policy decision but not its real consequences. Elections are held. The voter decides whether or not to reelect the incumbent. In the second period, the winning politician takes office and chooses the second-period policy.

Our analysis leads to the following results. First, reelection concerns may

\footnotetext{
${ }^{1}$ See Berganza (2000b) for a comprehensive survey.
} 
distort policy choices made by a good politician. In particular, we show that a good politician may choose not to implement a socially desirable policy if he sufficiently fears rent extraction in the future. The intuition behind the result is straightforward. Suppose voters dismiss the incumbent politician when implementation is observed. If a good politician chooses to implement a good policy, he knows that he will be dismissed and with some positive probability a bad politician will be in office in the future. On the other hand, preserving the status quo implies that the good policy will not be implemented. However, the benefits of doing so are that the good politician prevents a bad politician holding office in the future period. Accordingly not implementing a good policy today is the price to be paid for preventing a bad politician from holding office tomorrow. The inclination of a good politician not to implement a good policy depends on the scope of concerns over future rent appropriation, the likelihood that a bad politician will be in office, and the discrepancy between good and bad policy.

Second, reelection concerns may deter a bad politician from implementing a socially undesirable policy. This finding exhibits the disciplining effect of elections: elections reduce opportunistic behavior by bad politicians. The benefits to the voter are 1) a socially undesirable policy does not get implemented 2) rents are not appropriated in the current period. The result above is driven by a bad politician's re-election incentives. Also, elections give an incentive for a bad politician to postpone rent extraction. This accentuates the importance of tying politicians' performances in their final term with future prospect of their well-being.

Third, three types of equilibria exist: a disciplining equilibrium, a cynical equilibrium, and a timid equilibrium ${ }^{2}$. Which of these equilibria arises, depends on the extent to which the incumbent politician cares about the following: future prospects of rent extraction, likelihood that a bad politician enters office, and the significance of policy decisions in that good policy should be undertaken and bad policy should be maintained the status quo.

One equilibrium is particular striking. In the 'cynical' equilibrium, an attempt of a good politician to avoid future rent extraction by a bad politician may induce him not to implement a good policy. On the contrary, a bad politician does implement a good policy. When voters do not suffer much from rent extraction, a policy implemented by a bad politician may

\footnotetext{
${ }^{2}$ We have borrowed this term from Smart and Strum (2004).
} 
be beneficial to them. By ignoring the consequences of the future term, a bad politician appears to act more in line with the public interest than a good politician in the present term. As a good politician does not always implement a good policy while a bad politician does and sometimes brings benefit to the voters, the voters are not anymore able to infer a politician's motivation from observing politicians' behavior. Moreover, it is worth mentioning that even in this cynical world, we show that elections improve the likelihood that a good politician enters office in the future.

This paper is closely related to the literature on electoral accountability, pioneered by Barro (1973) and Ferejohn (1986), and further developed by Austen-Smith and Banks (1989) and Banks and Sundaram (1993). In this literature, the desire for reelection is at the heart of politicians. However, reelection incentives differ among models. For instance, politicians may desire to be in office because of ego rent as discussed in Rogoff (1990). The desire for reelection may also come from the expectation that holding office gives an opportunity to extract rents and/or to implement strongly preferred policies in the future. As we show in the paper, under the nature of asymmetric information where politicians with different motivations operate in our setting, differences in reelection incentives by good and bad politicians have important implication in politicians' behavior, voters' re-electing strategies, and the roles of elections.

Our paper also builds on Coate and Morris (1995). There voters have asymmetric information both about the effects of policies and about politicians' predispositions. They show that an inefficiently devious method to transfer resources through policy implementation rather than an efficient and simple method like a cash transfer may be employed. The similarity between their paper and ours is the importance of imperfect information on the part of voters. While their study focuses on the forms of making transfers by politicians, we instead focus on the functions of elections and policy choices under the asymmetric information above.

The remainder of the paper is structured as follows. The next section presents the model. Section 3 characterizes the equilibria and articulates the results. Section 4 concludes. 


\section{The model}

Consider a simple two-period game of incomplete information. In each period, there are two active players: an incumbent politician and a representative voter.

\subsection{Policies}

In each period $t=1,2$, a policy $X_{t}$ has to be decided whether it should be implemented, $X_{t}=1$ or preserved the status quo, $X_{t}=0$. The consequences of the policy are surrounded by uncertainty - i.e. they produce either bad or good consequences, $\mu_{t} \in\{-h, h\}$ with equal probability. An implemented policy with socially desirable consequences yields the positive benefit of $h$ while a policy with socially undesirable consequences yields the negative benefit of $-h$.

\subsection{Incumbent politician}

The incumbent politician observes $\mu_{t}$. There are two types of politicians, $\theta_{t} \in\{G, B\}$. Incumbent politician's type is his private information. With probability $\omega$, the politician is good $(\theta=G)$; with probability $1-\omega$, he is bad $(\theta=B)$. A bad politician wants to appropriate rent. Specifically we assume that if a policy is implemented by a good politician, the payoff to the representative voter (henceforth the voter) equals $\mu$. When a bad politician implements a policy, the payoff to the voter is $\mu_{t}-\gamma R$, where $R$ denotes the extracted rent and $\gamma$ measures how much the voter suffers from the extraction of the rent. When the status quo is maintained, the payoff to the voter and the incumbent politician, irrespective of his type, equals zero. A good politician cares about the public interest. When $X_{t}=1$, his payoff equals $\mu_{t}$. When a bad politician implements a policy, his payoff equals $\mu_{t}+R$. Notice that the appropriation of rent requires $X_{t}=1$. We assume that $-h+R>0$, implying that a bad politician has an incentive to implement a socially undesirable policy $\left(\mu_{t}=-h\right)$ to extract the rent. The incumbent politician's preferences are summarized by:

$$
\begin{aligned}
& U_{G}\left(X_{t}=1\right)=\mu_{t} \\
& U_{B}\left(X_{t}=1\right)=\mu_{t}+R \\
& U_{G}\left(X_{t}=0\right)=U_{B}\left(X_{t}=0\right)=0
\end{aligned}
$$




\subsection{Representative voter}

The representative voter is concerned about implementation outcomes which are composed of two parts: policy outcomes itself and rent appropriation if a bad politician is in office. The voter's preferences are thus given by:

$$
\begin{aligned}
& U_{V}\left(X_{t}=1\right)=\mu_{t}-\gamma R \\
& U_{V}\left(X_{t}=0\right)=0
\end{aligned}
$$

where $\gamma$ captures the extent to which the voter suffers from the extraction of the rent. The payoff to the voter is normalized to zero if the status quo is retained. At the end of period 1, elections are held. The voter can keep the incumbent $(v=0)$ or dismiss him $(v=1)$. If the incumbent is dismissed, then in period 2 the politician will be good with probability $\omega$ and bad with probability $1-\omega$. When voting, the voter observes the decision on $X_{1}$ but does not observe outcomes $\left(\mu_{t}\right.$ and $R$ ). As we will show below, the reason for holding elections in our model is twofold. First, it increases the probability that in period 2 a good incumbent holds office. Second, elections may keep a bad politician from appropriating a rent in period 1.

\subsection{Timing}

Nature first determines $\mu_{1} \in\{-h, h\}$ and the incumbent politician discovers his type from $\theta \in\{G, B\}$. The incumbent observes $\mu_{1}$ and decides whether to implement the policy $\left(X_{1}=1\right)$ or to preserve the status quo $\left(X_{1}=0\right)$. The voter observes the policy decision made by the incumbent. Subsequently the voter decides whether to re-elect the incumbent $(v=0)$ or to dismiss $\operatorname{him}(v=1)$. The second period is identical to the first period, with a new policy, $X_{2}$, a new state of the world, $\mu_{2} \in\{-h, h\}$, and, if $v=1$, a new incumbent. To simplify notation, we abstract from discounting the future. ${ }^{3}$

\footnotetext{
${ }^{3}$ We are aware that with some discounting, a bad politician may have an incentive to take all rents in period 1.
} 
Table 1. The description of the model

Players: The incumbent politician and the representative voter Timing:

Period 1

- Nature determines $\mu_{1} \in\{-h, h\}$ and $\theta_{1} \in\{G, B\}$.

- The incumbent observes $\mu_{1}$ and chooses $X_{1} \in\left\{X_{1}=0, X_{1}=1\right\}$.

- The voter observes $X_{1}$ and then chooses $v \in\{v=0, v=1\}$.

Period 2

- Nature determines $\mu_{2} \in\{-h, h\}$; and if $v=1, \theta_{2} \in\{G, B\}$.

- The winning incumbent observes $\mu_{2}$ and chooses $X_{2} \in\left\{X_{2}=0, X_{2}=1\right\}$.

- The game ends.

Payoffs:

$U_{G}\left(X_{t}=1\right)=\mu_{t} ; U_{G}\left(X_{t}=0\right)=0$.

$U_{B}\left(X_{t}=1\right)=\mu_{t}+R ; U_{B}\left(X_{t}=0\right)=0$.

$U_{V}\left(X_{t}=1\right)=\mu_{t}-\gamma R ; U_{V}\left(X_{t}=0\right)=0$.

Assumptions:

$-h+R>0$.

\section{Analysis}

\subsection{Equilibrium in the second-period game}

The strategies of the two types of politician in the second period directly follow from the assumptions made above. The assumption that $-h+R>0$ implies that in period 2 a bad politician chooses $X_{2}=1$, irrespective of the state of the world. By assumption, a good politician opts for $X_{2}=1$ if and only if $\mu_{2}=h$. Clearly, it is in the voter's interest to have a good politician in office in period 2 . 


\subsection{Equilibrium in the first-period game}

An important feature of our model is that relative to a good politician, a bad politician is biased towards implementation. We therefore suppose that the voter dismisses the incumbent, $v=1$, if and only if $X_{1}=1$. Later we will verify whether this strategy is an optimal response for the voter.

Consider a good politician in period 1 . Suppose $\mu_{1}=-h$. Then, clearly the good politician has no incentive to choose $X_{1}=1$ as a bad policy would be implemented and with probability $1-\omega$ the good politician would be replaced by a bad politician. Thus, if $\mu_{1}=-h$, then it is an optimal response for the good politician to choose $X_{1}=0$. Now suppose $\mu_{1}=h$. The good politician faces a trade-off. On the one hand, choosing $X_{1}=1$ implies that he will be dismissed. Then, with probability $1-\omega$ a bad politician will be in office in period 2. On the other hand, $X_{1}=0$ implies that a good policy will not be implemented. Anticipating his behavior in period $2, X_{1}=0$ yields an expected payoff to the good politician (and to the voter) equal to:

$$
U_{G}\left(X_{1}=0 \mid \mu_{1}=h\right)=\frac{1}{2} h
$$

Choosing $X_{1}=1$ yields an expected utility:

$$
U_{G}\left(X_{1}=1 \mid \mu_{1}=h\right)=h+\omega \frac{1}{2} h-(1-\omega) \gamma R
$$

A comparison between (3) and (4) shows that $X_{1}=1$ increases period 1 utility $(h)$, but reduces period 2 utility. Clearly, $X_{1}=1$ yields a higher payoff than $X_{1}=0$ if:

$$
\gamma R<\frac{1}{2} \frac{1+\omega}{1-\omega} h
$$

The intuition behind (5) is simple. The benefits of choosing $X_{1}=0$ is that the good politician prevents a bad politician from entering office in period 2 . The higher $\gamma R$ is, the higher the costs of a bad politician are. Moreover, the lower $\omega$ is, the higher the probability is of a bad politician entering office in period 2 when choosing $X_{1}=1$. Finally, the higher $h$ is, the more important it is that a policy is implemented when $\mu_{1}=h$ and not implemented when $\mu_{1}=-h$. Thus, a lower $\gamma R$, a higher $\omega$, and a higher $h$ widen the range of parameters for which a good politician chooses $X_{1}=1$. If (5) is violated, then a good politician always chooses $X_{1}=0$. Choosing $X_{1}=0$ when $\mu_{1}=h$ (not implementing a good policy) is the price to be paid for preventing a bad politician to take office in period 2 . 
Lemma 1 Suppose that the voter dismisses the incumbent, $v=1$, if $X_{1}=1$. Then, a good politician may opt for not implementing a good policy to avoid future rent extraction.

Now consider a bad politician. Suppose $\mu_{1}=-h$. Then, $X_{1}=1$ yields a payoff equal to:

$$
U_{B}\left(X_{1}=1 \mid \mu_{1}=-h\right)=-h+R+\omega \frac{1}{2} h-(1-\omega) \gamma R
$$

and $X_{1}=0$ yields:

$$
U_{B}\left(X_{1}=0 \mid \mu_{1}=-h\right)=R
$$

Consequently, $X_{1}=1$ delivers a higher payoff than $X_{1}=0$ if:

$$
\gamma R<\frac{\frac{1}{2} \omega-1}{1-\omega} h
$$

It is easy to see that condition ( 7 ) is always violated. Hence, when $\mu_{1}=-h$, it is an optimal response for a bad politician to choose $X_{1}=0$. This finding illustrates the potential disciplining function of elections. Elections lead a bad politician to abstain from implementing a socially undesirable policy. The benefit for the voter is twofold. First, a bad policy is not implemented. Second, in period 1 rents are not appropriated. The reason why $R$ discourages a bad politician from implementing an undesirable policy is that a bad politician also does not want to be reigned by a bad politician. As a result, elections give an incentive to a bad politician to postpone rent appropriation. Now suppose $\mu_{1}=h . X_{1}=1$ yields a payoff:

$$
U_{B}\left(X_{1}=1 \mid \mu_{1}=h\right)=h+R+\omega \frac{1}{2} h-(1-\omega) \gamma R
$$

Again, $X_{1}=0$ yields $R$. Consequently, a bad politician chooses $X_{1}=1$ if:

$$
\gamma R<\frac{2+\omega}{2(1-\omega)} h
$$

Equation (9) shows that a high rent $(\gamma R)$, a low value of $h$, and a low value of $\omega$ may keep a bad politician from choosing $X_{1}=1$ and appropriating a rent in period 1.

Lemma 2 Suppose that the voter dismisses the incumbent, $v=1$, if $X_{1}=1$. Then, a bad politician never implements a policy when $\mu_{1}=-h$, and may abstain from implementing a policy when $\mu_{1}=h$. 
On the basis of (5) and (9), three situations can be distinguished.

A cynical equilibrium ((5) is violated and (9) is satisfied)

If (5) is violated and (9) is satisfied, then in period 1 a good politician retains the status quo, irrespective of the state of the world, and a bad politician implements the policy only if $\mu_{1}=h$. Notice that given these strategies, the assumed voting rule is an optimal response. Voting for the incumbent $(v=0)$ if and only if $X_{1}=0$ maximizes the probability that in period 2 a good politician holds office. If $\gamma$ is sufficiently small, then the voter benefits from a policy that is implemented by a bad politician $(h-\gamma R>0)$. Accordingly, when we ignore the consequences for period 2 , in period 1 a bad politician acts more in line with the voter's interest than a good politician (hence a cynical equilibrium). The reason for this is that a good politician does not implement a socially desirable policy. The cost of giving up a desirable policy is smaller than the benefit of having a good politician in office in period 2 . The following proposition summarizes this phenomenon.

Proposition 1 Suppose $\gamma R>\frac{1}{2} \frac{1+\omega}{1-\omega} h$ and $\gamma R<\frac{2+\omega}{2(1-\omega)} h$. Then an equilibrium exists in which $v=0$ if and only if $X_{1}=0$; a good politician chooses $X_{1}=0$, irrespective of $\mu_{1}$; and a bad politician chooses $X_{1}=1$ if and only if $\mu_{1}=h$.

It is worth emphasizing that in the cynical equilibrium elections have two constructive functions. First, elections discipline bad politicians. In period 1, policies that are socially undesirable are not implemented. Without elections, a bad politician would always choose $X_{1}=1$. Second, elections improve the probability that in period 2 a good politician holds office. Without elections, this probability would be $\omega$; with elections, it is $\omega+\frac{1}{2}(1-\omega)$.

A timid equilibrium (both (5) are (9) violated)

If (5) and (9) are both violated, then in period 1 both types of politicians retain the status quo, irrespective of the state of the world. Is the voting rule "re-elects the incumbent if and only if $X_{1}=0$ " an optimal response to the politicians' strategies. The answer to this question depends on the out of equilibrium belief when $X_{1}=1$. As bad politicians are relatively biased towards $X_{1}=1$, a natural out of equilibrium belief is $\operatorname{Pr}\left(\theta_{1}=B \mid X_{1}=1\right)=$ 1. With this belief, the strategies of the two types of politicians mentioned 
above in conjunction with the assumed voting rule form an equilibrium of the period 1 game. A timid equilibrium describes a situation in which politicians remain passive. From the conditions (5) and (9), it directly follows that a timid equilibrium exists if the voter suffers much from rent appropriation (high $\gamma R$ ), the chances of having a bad politician are high (low $\omega$ ), and the value of good and bad policies do not differ much (low $h$ ).

Proposition 2 Suppose $\gamma R>\frac{1}{2} \frac{1+\omega}{1-\omega} h$ and $\gamma R>\frac{2+\omega}{2(1-\omega)} h$. Then an equilibrium exists in which $v=0$ if and only if $X_{1}=0$; a good politician as well as a bad politician choose $X_{1}=0$, irrespective of $\mu_{1}$.

In a timid equilibrium, elections only have one function: disciplining bad politicians. Since bad and good politicians act in the same way in period 1, elections do not help to increase the probability that a good politician holds office in period 2.

A disciplining equilibrium (both (5) are (9) satisfied)

If (5) and (9) are both satisfied, then in period 1 both types of politicians retain the status quo, if and only if $\mu_{1}=h$. When $h-\gamma R>0$, these strategies imply that good policies are implemented and bad policies are not implemented. Is $v=0$ if and only if $X_{1}=0$ a best response to these strategies? The answer is in the affirmative, as the policy implementation decision does not contain information about the politician's type. In fact, at elections the voter is indifferent between re-electing and dismissing the incumbent.

Proposition 3 Suppose $\gamma R<\frac{1}{2} \frac{1+\omega}{1-\omega} h$ and $\gamma R<\frac{2+\omega}{2(1-\omega)} h$. Then an equilibrium exists in which $v=0$ if and only if $X_{1}=0$; a good politician as well as a bad politician choose $X_{1}=1$ if and only if $\mu_{1}=h$.

As in the timid equilibrium, in the disciplining equilibrium elections only serve the purpose of disciplining bad politicians in period 1 .

All three equilibria are illustrated in Figure 1. 


\begin{tabular}{ccc}
$\frac{(1+\omega) h}{2(1-\omega)}$ & $\frac{(2+\omega) h}{2(1-\omega)}$ \\
\hline $\begin{array}{c}\text { Disciplining } \\
\text { equilibrium }\end{array}$ & $\begin{array}{c}\text { Cynical } \\
\text { equilibrium }\end{array}$ & $\begin{array}{c}\text { Timid } \\
\text { equilibrium }\end{array}$ \\
$G:\left(X_{1}^{*}\left|h, X_{1}^{*}\right|-h\right)=(1,0)$ & $G:\left(X_{1}^{*}\left|h, X_{1}^{*}\right|-h\right)=(0,0)$ & $G:\left(X_{1}^{*}\left|h, X_{1}^{*}\right|-h\right)=(0,0)$ \\
$B:\left(X_{1}^{*}\left|h, X_{1}^{*}\right|-h\right)=(1,0)$ & $B:\left(X_{1}^{*}\left|h, X_{1}^{*}\right|-h\right)=(1,0)$ & $B:\left(X_{1}^{*}\left|h, X_{1}^{*}\right|-h\right)=(0,0)$
\end{tabular}

Figure 1. Characterization of the three equilibria

\section{Concluding remarks}

In this paper, we have developed a simple two-period model to gain insights into the importance of differences in motivation among politicians and its implications for understanding the role of elections and explaining policy choices. We derive the following results. First, our analysis suggests that the disciplining function of elections plays its role in all political equilibria. Elections discipline opportunistic politicians to abstain from implementing a socially undesirable policy. Without elections, they would always implement any policy irrespective of the state of the world. Second, as shown in the cynical equilibrium, elections perform another function. They improve the likelihood that a good politician enters office tomorrow. A striking result in this equilibrium is that a bad politician, by implementing a socially desirable policy, may instead act more in tune with the public interest as a good politician chooses not to implement a socially desirable policy. Accordingly, when voters care sufficiently less about rent extraction, the policy implemented by a rent-seeking politician may benefit to the voters.

Additionally, elections may also create an incentive for an opportunistic politician to postpone an extraction of the rents. This reminds us that elections alone do not guarantee proper functioning of modern democracies. Other complementary institutional arrangements are necessary. Persson, Roland, and Tabellini (1997) show that joint efforts between elections and separation of powers between legislative and executive bodies help prevent an abuse of power by opportunistic politicians. Finally, to overcome the lame duck problem, it might be worth paying attention to an institutional arrangement inducing last-period government to condition a future prospect of its well-being on its last term performance. 


\section{References}

[1] Austen-Smith, D. and Banks, J. (1989). Electoral accountability and incumbency. In Ordeshook, P.C. (Ed), Models of strategic choice in politics, Ann Arbor, University Michigan Press.

[2] Banks, J. and Sundaram, R. (1993). Adverse selection and moral hazard in repeated elections. Proceedings of the Seventh International Symposium in Economic Theory and Econometrics: 295-311. Cambridge, MA: Cambridge University Press.

[3] Banks, J. and Sundaram, R. (1998). Optimal retention in agency problems. Journal of Economic Theory 82: 293-323.

[4] Barro, R.J. (1973). The control of politicians: An economic model. Public Choice 14: 19-42.

[5] Berganza, J.C. (2000a). Two roles for elections: Disciplining the incumbent and selecting a competent candidate. Public Choice 105: 165-193.

[6] Berganza, J.C. (2000b). Politicians, voters and electoral process: An overview. Investigaciones económicas XXIV(3): 501-543.

[7] Besley, T. and Case, A. (1995). Does electoral accountability affect economic policy choices?: Evidence from gubernatorial term limits. Quarterly Journal of Economics 112: 1163-1202.

[8] Besley, T. and Coate, S. (1997). An economic model of representative democracy. Quarterly Journal of Economics CXII: 85-114.

[9] Besley, T. (2004). Principled agents. Memo, LSE.

[10] Coate, S. and Morris, S. (1995). On the form of transfers to special interests. Journal of Political Economy 103(6): 1210-1235.

[11] Ferejohn, J.A. (1986). Incumbent performance and electoral control. Public Choice 50: 5-26.

[12] Le Borgne, E. and Lockwood, B. (2003). Do elections always motivate incumbents? experiments vs. career concerns. IMF Working Paper, $\mathrm{WP} / 03 / 57$. 
[13] Persson, T. and Tabellini, G. (2000). Political economics: Explaining economic policy. Cambridge, MA: MIT Press.

[14] Rogoff, K. (1990). Equilibrium political budget cycles. American Economic Review 80: 21-36.

[15] Smart, M. and Sturm, D. (2004). Term limits and electoral accountability. Discussion Paper, CESifo.

[16] Suurmond, G., Swank, O.H. and Visser, B. (2004). On the bad reputation of reputational concerns, Journal of Public Economics 88: 28172838 . 